\title{
Self Perceptions of Students' Humanities-Based Skills IN AN ENGINEERING PROGRAM: OVERVIEW OF A LONGITUdiNAL STUDY'S FIRST TWO YEARS (2017-2019)
}

\author{
Laura Patterson \\ University of British Columbia \\ Laura.patterson@ubc.ca
}

\begin{abstract}
This paper is a continuation of research from a previous paper presented to CEEA on a three-year longitudinal study aimed at assessing engineering accreditation non-technical skills at a medium sized engineering school at a large research university. The goal of this longitudinal study is to improve the assessment of these non-technical graduate attributes and test a metric to do so.

The Likert-style survey focuses on engineering students self-perceptions of teamwork, communication skills, engineering ethics, professionalism, and lifelong learning in order to gather quantitative data that can be analyzed for trends. Self-perceptions are the focus of this study because student self-efficacy has been found to be correlated with student success over the long term. The study has been conducted through pre-and post-surveys testing whether engineering students' self-assessment of their abilities in those areas increased or decreased from year to year.
\end{abstract}

Currently, the longitudinal study has only just completed data collection for its final year of the threeyear study, so the focus of this paper will be adding the results of the second year to the first, which were presented to CEEA last year. This paper analyzes the data gathered in the second year of the longitudinal study and continue the analysis of those results to explore what they can offer to our understanding of non-technical engineering graduate attributes. These findings are not meant to replace other initiatives, but to offer another metric to examine the effectiveness of engineering programs and meeting non-technical accreditation requirements.

Keywords: CEAB graduate attributes, student selfperceptions, longitudinal study, engineering education

\section{INTRODUCTION}

Humanities based graduate attributes (eg/ communication, professionalism and teamwork) can be difficult to quantify for engineering programs, so they are always looking for ways to measure them. Engineering programs employ many curricular and co-curricular methods to help address these attributes; however, studies have noted that these humanities-focused accreditation requirements are difficult to isolate and assess [7].

This research assesses students' self-perceptions at different points in their program as a means to measure the effectiveness of engineering programs at meeting nontechnical graduate attributes. Student self-perceptions can have an element of bias; however, student self-efficacy has been correlated with long-term student success $[1,6]$. As well, this metric should not substitute other initiatives for establishing curriculum effectiveness, but instead be used to offer a fuller picture to understand how students view their own abilities in these graduate attributes that may then lead to long term success in those areas.

This three-year longitudinal study was first run as a pilot in 2016 to test a co-curricular initiative at the University of British Columbia's School of Engineering to integrate humanities-focused graduate attributes into an engineering program. This initiative, Introduction to Engineering (i2E), introduces all first-year engineering students to students to core concepts that will support their academic and professional success in areas such as individual and teamwork skills, professionalism, ethics and equity, and lifelong learning [4]. Though i2E originally was embedded in the first year of study, an online version was integrated in the second year of the study.

The pilot of this study found the metric to be useful in understanding the co-curricular initiative, and was developed into a three-year longitudinal study that included all years of study beginning September 2017. The purpose of the longitudinal study is to improve instructors' understanding of the perceptions of engineering students across all years of study to determine if and how these perceptions change after exposure to such initiatives the first year. At the time of the writing of this paper, the longitudinal study data collection for all three years has just completed, but researchers only have access to the data from the first two years. This paper is a follow up to a CEEA paper on the first year of data [3], so the focus of this paper will be limited to the results of the second year, 
2018/2019. Some comparisons will be made to first year results; however, these observations will be limited until all three years of data can be analyzed.

\section{RESEARCH DESIGN AND METHODS}

The research design and methods in the 2018-2019 data collection were very similar to the 2017-2018 data collection [3]. Two phases of data collection in the second year of the study were used. In the first phase in September of 2018, the Year 1 students were surveyed in order to get a baseline of their self-perceptions upon entry into their engineering program. The second phase of data collection took place at the end of term in April of 2019. The Year 1 students were surveyed again using the same 14 Likertstyle questions from the first phase. In addition, students in Years 2, 3, and 4 of their engineering program were also surveyed to see how these students perceived their abilities in the same attributes. In this second year of the study, much of the Year 2 cohort will have been exposed to i2E, from the previous year, and much of the Year 3 cohort will have been exposed to the original i2E program when the pilot study was run. With a rare exception, the Year 4 students will not have been directly exposed to i2E programming during their engineering education.

Students were excluded from the study if they declined to consent to the study, or agreed, but did not complete the whole survey. As a result, in the pre survey for Year 1 in September $2018 \mathrm{n}=91$, and in the post survey run in April 2019 are as follows: Year $1 \mathrm{n}=82$, Year $2 \mathrm{n}=97$, Year 3 $\mathrm{n}=58$, and Year $4 \mathrm{n}=54$.

This study has been approved by the institution's behavioral research ethics board.

The survey used was the same as was used in the 20172018 data collection to understand participants' selfefficacy of humanities-based graduate attributes, as one indicator of competency. [3]. The online survey was comprised of 14 Likert-style questions on a 4-point scale, ( 4 = strongly agree, $3=$ agree, $2=$ disagree, $1=$ strongly disagree), about the following attributes: Teamwork, Leadership, Ethics, Professionalism, Lifelong Learning, Community Responsibility, and Communication Skills. Some of these attributes directly relate to Canadian Engineering Accreditation Board's (CEAB) graduate attributes (i.e., Professionalism), while others isolate subissues within a broader attribute (i.e., Community Responsibility) [2]. This study focuses on quantitative metrics to calculate the overall aggregated trends of students' self-efficacy in these areas. Likert statements included both positive and negative wordings to increase the validity of the findings. Though the pairs of questions do not encompass all elements of each non-technical graduate attribute tested as indicated by the CEAB, the question pairs do indicate essential skills that are necessary to demonstrate these graduate attributes [2].

\section{RESULTS AND DISCUSSION}

The data from the second year of the longitudinal study on each of the attributes that student participants were surveyed on, Teamwork, Leadership, Ethics, Professionalism, Lifelong Learning, Community Responsibility, and Communication skills, are presented here.

Figure 1 shows the participants' average self-efficacy ratings for teamwork. Students across all years identified as agreeing to strongly agreeing in their ability to work as a productive member of a team overall, increasing slightly from year to year. They disagree that they struggle to deal with conflict within their teams. This pattern was very similar in the results from 2017-2018 [3], though no increase from year to year was observable then.

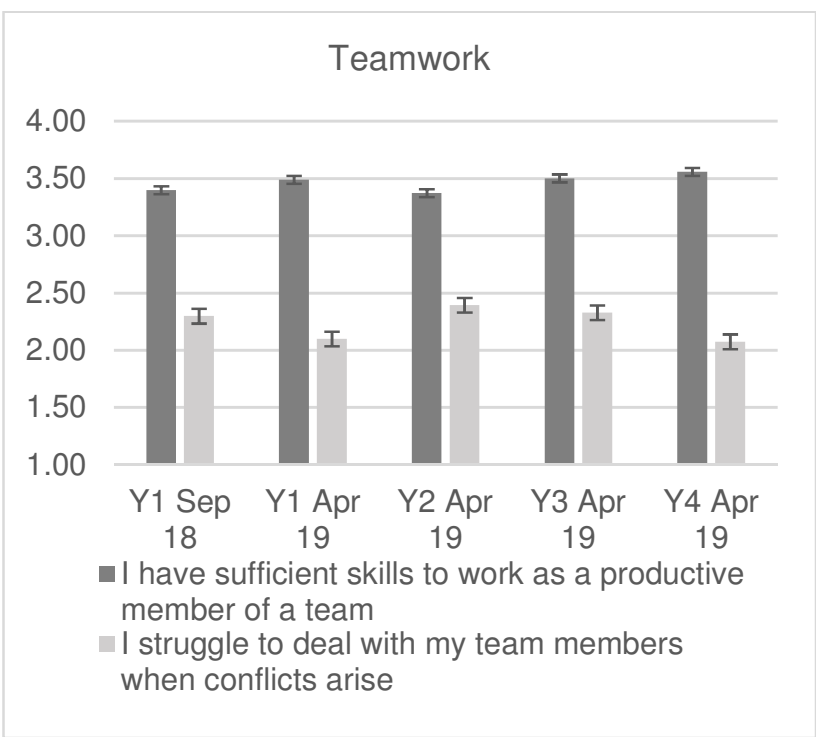

Fig. 1. Students' self-efficacy surrounding teamwork across all years of study (2018-2019 data).

Figure 2 shows participants' self-efficacy beliefs of their leadership abilities. Participants consistently agree, though increasing slightly from year to year, that they are aware of their strengths and weaknesses as a leader, and disagree that they struggle to understand other people's point of view. The difference in participants' perception of self-efficacy between the positively and negatively worded statements seems to increase somewhat as students progressed in their programs. 


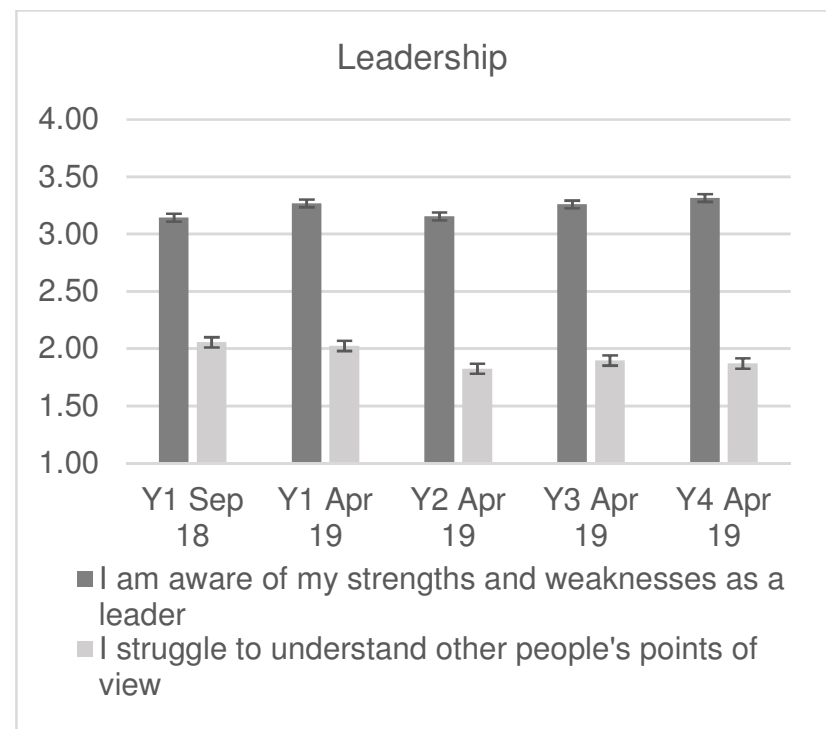

Fig. 2. Students' self-efficacy surrounding leadership across all years of study (2018-2019 data).

Figure 3 shows participants' self-efficacy in knowing engineering ethical codes. There was an increase from Year 1 students being almost in the middle between disagreeing and agreeing to Year 4 students in the study clearly agreeing.

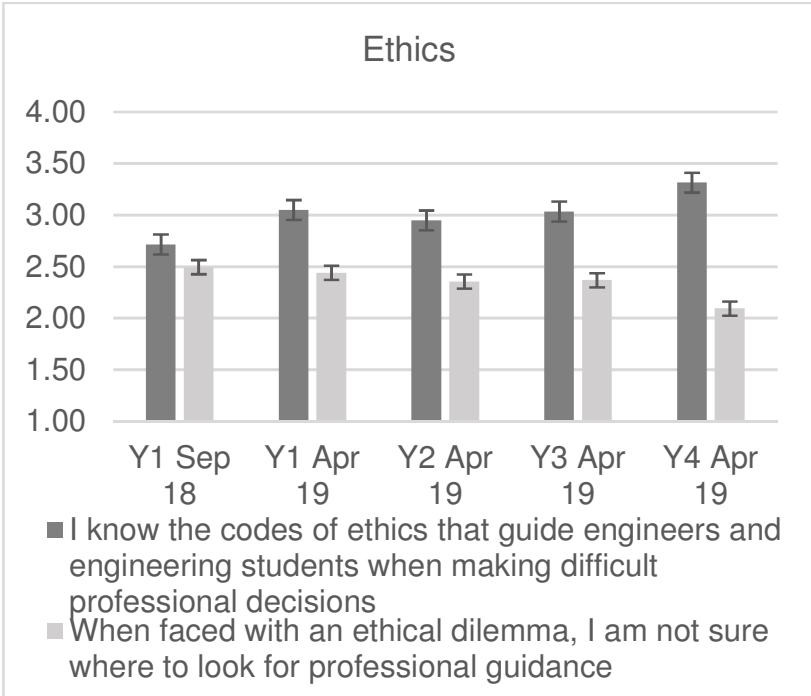

Fig. 3. Students' self-efficacy surrounding ethics across all years of study (2018-2019 data).

A similar decrease is observed as Year 1 students in September again rank themselves between agreeing and disagreeing that when faced with an ethical dilemma that they are not sure where to look for professional guidance to Year 4 students clearly disagreeing with that statement.

This progressive divergence between the rankings of the positively and negatively worded statements as students progress in their programs was also observed in the data for 2017-2018 [3]. In terms of professionalism, participants ranked themselves consistently between agree and strongly agree in terms of their beliefs that they must contribute to a solution to a problem, even if they are not at fault (see Figure 4). Though not necessarily a mutually exclusive statement, students across all years of study were split between agreeing and disagreeing, though closer to agreeing, that when something goes wrong, it is the responsibility of the person at fault needs to fix it.

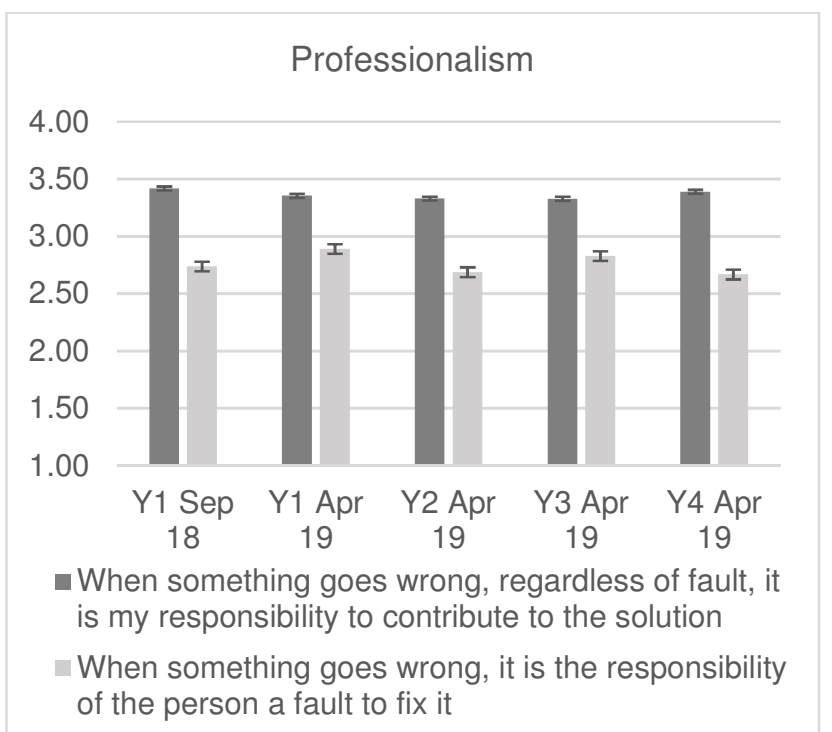

Fig. 4. Students' self-efficacy surrounding professionalism across all years of study (2018-2019 data).

When participants were asked about their desire to pursue educational opportunities outside their formal education, or lifelong learning, they consistently agreed across all years that they were interested in doing so (see Figure 5). Participants in all years of study for the most part strongly disagreed that they had no interest in learning outside of their formal education. This trend was also observed in the data from 2017-2018 [3]; however, the 2018-2019 data shows a slight increase in student tendencies towards lifelong learning that was not observed in the previous year. 


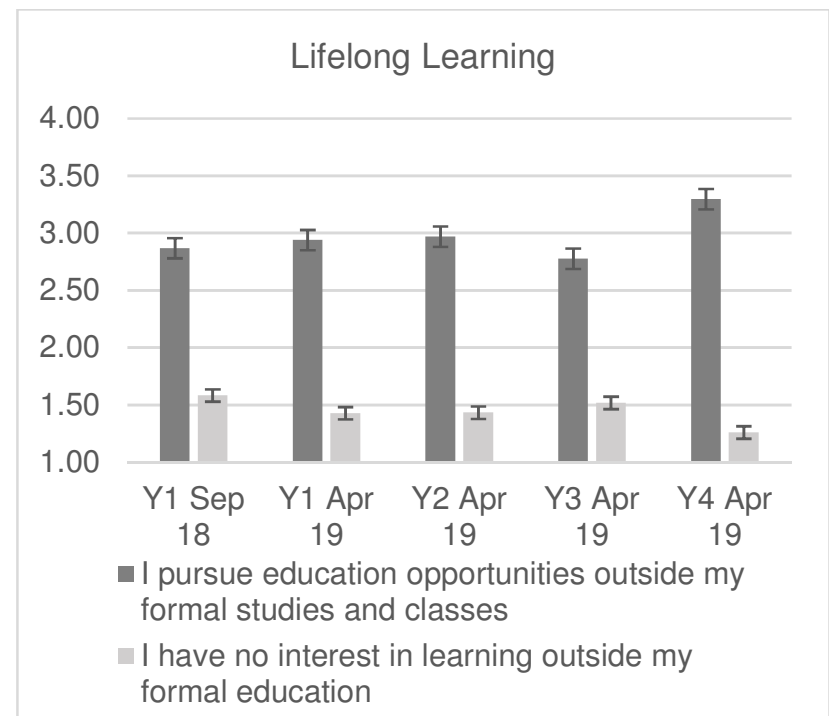

Fig. 5. Students' self-efficacy surrounding lifelong learning across all years of study (2018-2019 data).

Figure 6 demonstrates that participants across all years ranked themselves as between agreeing and disagreeing with statements regarding whether they make a decision based on the effect on the community or on themselves. In Year 1 students in September, self-interest is ranked slightly higher than community responsibility; however, in all other years of study community responsibility is ranked slightly higher.

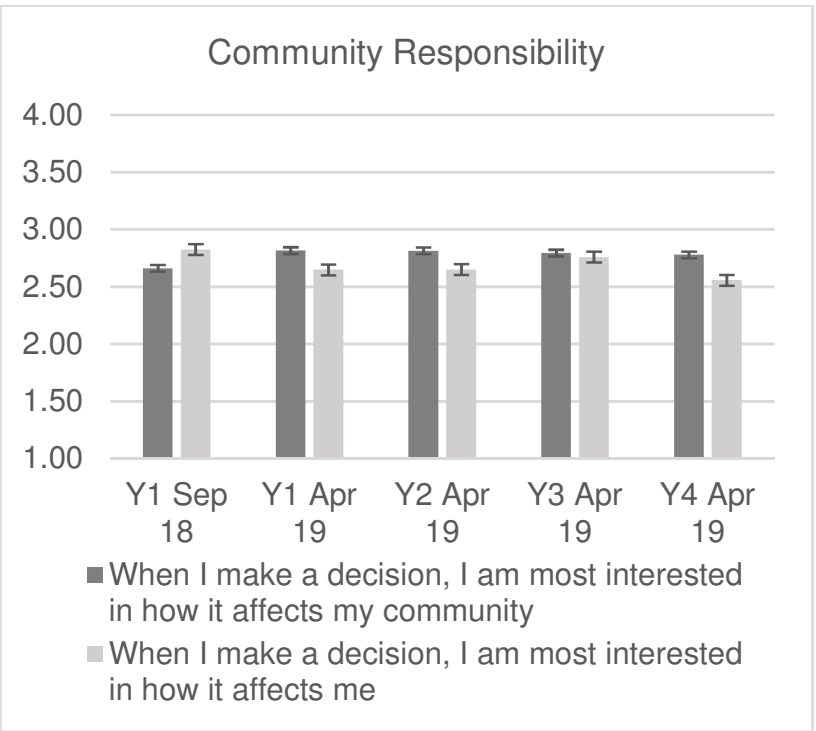

Fig. 6. Students' self-efficacy surrounding community responsibility across all years of study (2018-2019 data).

As seen in Figure 7, participants' self-efficacy in their communication skills increases consistently from year to year as they increasingly agree with the statement that they are able to communicate as an engineer in a variety of situations. Similarly, there is a corresponding decrease from year to year in their agreement with the statement that they are not sure if they can communicate as an engineer. The data from 2017-2018 also reflects a similar trend [3].

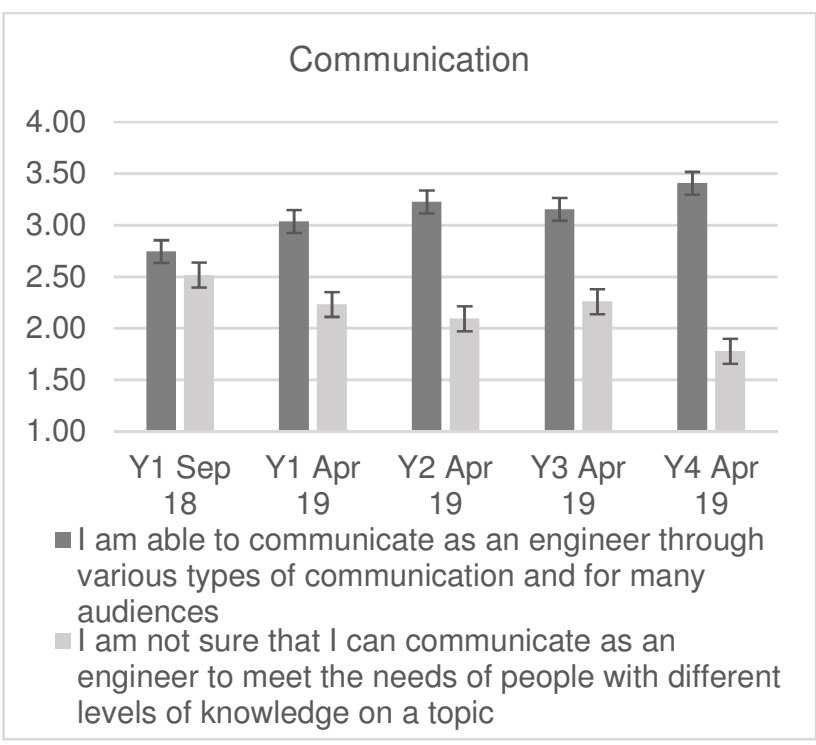

Fig. 7. Students' self-efficacy surrounding communication across all years of study (2018-2019 data).

Some overall patterns that were observed in the 20172018 data are reflected in the 2018-2019 data. For example, the increasing differences from the positively worded statements to the negatively worded statements (ie. Ethics, Communication) reinforces the earlier observation that aspects of their engineering education may be increasing student participants' self-efficacy in those areas. The large gaps between the positively worded statements and the negatively worded statement (ie. Teamwork, Leadership, Lifelong Learning) are still present in the 2018-2019 data as they were in the 2017-2018 data; however, there are slight increases noted in self efficacy in the 2018-2019 data that were not observable in the previous year. This increase may suggest that their program could be affecting these attributes; however, analysis of the data from the final year of the longitudinal study would be necessary to see if that trend continues. Similar to the 2017-2018 data, the 20182019 data reinforces that Professionalism and Community Responsibility statements can be perceived as not entirely mutually exclusive statements. This observation is made based on the similarity in levels of agreement to both statements and the consistency of student responses across all years in both of these attributes.

\section{CONCLUSIONS}

Though there are limitations to these conclusions as student self-perceptions, self-efficacy is an important metric to consider when anticipating students' future success in these humanities-based skills [1, 6]. In addition, more confidence can be put in these findings as several 
trends observed in the first year of the study are somewhat mimicked in the data in the second year. These similar trends include observations of increased self-efficacy in engineering ethics and communication skills. There are still relatively stable self-perceptions of teamwork and leadership skills, in addition to their interest in lifelong learning though in the 2018-2019 data a slight increase was observed from students' progress year to year in their program. There are still baselines missing for some years of the program to compare individual cohorts of students, so the observations noted in this paper are only a preliminary understanding of the data until the cohorts can be more appropriately isolated in further analysis of the data from the entire longitudinal study. Again, the 20182019 data suggests that professionalism and community responsibility are more complex for participants as seemingly opposite statements are not mutually exclusive. Future qualitative research to explore students' perceptions of those attributes would help educators more fully understand how students perceive their importance.

As the second year of the study, the findings are still limited; however, the similar trends observed from the 2017-2018 data to the 2018-2019 data are encouraging that this metric is effective. Even the preliminary understanding of student perceptions of the abilities in these humanitiesbased attributes from the first year results proved useful in providing a fuller picture when integrated into the University of British Columbia's School of Engineering's accreditation report. In addition, this survey has already been used in collaboration with an institution in the United States to test students' self-efficacy after participating in a curricular initiative [5].

The next steps for this research are analyzing the final year of data and comparing the findings with the first two years for more significant trends, and a fuller analysis of the effectiveness of i2E based on the entire data set of the longitudinal study. Future studies should include qualitative research to use students' own language to understand trends observed in the data, particularly surrounding professionalism and community responsibility.

\section{Acknowledgements}

This work would not be possible without Carolyn Labun who created the original i2E program, and Jannik

Eikenaar, Cathi Shaw, Megan Lochhead, and Samantha Luckow who were involved in the design and implementation of $\mathrm{i} 2 \mathrm{E}$ and the longitudinal study

\section{References}

[1] Albert Banduara, "Self-efficacy: Toward a unifying theory of behavioral change," Psychological Review, vol. 84, no. 2, pp. 191-215, 1977.

[2] Engineers Canada, Canadian Engineering Accreditation Board: 2017 Accreditation Criteria and Procedures, 2017. Retrieved March 3, 2019 from https://engineerscanada.ca/sites/default/files/accreditat ion-criteria-procedures-2017.pdf

[3] Laura Patterson, "Self Perceptions of Students' Humanities-Based Skills in an Engineering Program; Overview of First Year Results," in Proc. of CEEA Canadian Engineering Education Conf., (Ottawa, ON; 9-12 June 2019), 5 pp, 2019.

[4] Laura Patterson, Jannik Eikenaar, and Carolyn Labun, "Teaching and assessing 'Lifelong learning" in engineering communication courses," in Proc. of CEEA Canadian Engineering Education Conf., (Halifax, NS; 19-22 June 2016), 7 pp, 2016.

[5] Laura Patterson and Elaine Wisniewski, "Baseline selfefficacy of graduate attribute competencies in first-year engineering students in the United States and Canada," in Proc. IEEE Professional Communication Conference (Toronto, ON; 22-25 July 2018), 2 pp, 2018.

[6] Dale H. Schunk, "Self-efficacy and academic motivation," Educational Psychologist, vol. 26, no. 3 \& 4, pp. 207-231, 1991.

[7] Larry J. Shuman, Mary Besterfield-Sacre, and Jack McGourty, " The ABET 'Professional Skills' - can they be taught? Can they be assessed?" Journal of Engineering Education, vol. 94, no. 1, pp. 41-51, 2005. 